\title{
Remote sensing of intertidal morphological change in Morecambe Bay, U.K., between 1991 and 2007
}

Article

Accepted Version

Mason, D. C., Scott, T. R. and Dance, S. L. (2010) Remote sensing of intertidal morphological change in Morecambe Bay, U.K., between 1991 and 2007. Estuarine, Coastal and Shelf Science, 87 (3). pp. 487-496. ISSN 0272-7714 doi: https://doi.org/10.1016/j.ecss.2010.01.015 Available at https://centaur.reading.ac.uk/4726/

It is advisable to refer to the publisher's version if you intend to cite from the work. See Guidance on citing.

Published version at: http://dx.doi.org/10.1016/j.ecss.2010.01.015

To link to this article DOI: http://dx.doi.org/10.1016/j.ecss.2010.01.015

Publisher: Elsevier Ltd

All outputs in CentAUR are protected by Intellectual Property Rights law, including copyright law. Copyright and IPR is retained by the creators or other copyright holders. Terms and conditions for use of this material are defined in the End User Agreement.

www.reading.ac.uk/centaur 
Central Archive at the University of Reading

Reading's research outputs online 


\title{
1 SHORT COMMUNICATION
}

\section{2}

\section{Remote sensing of intertidal morphological change in Morecambe Bay, U.K., between 1991 and 2007.}

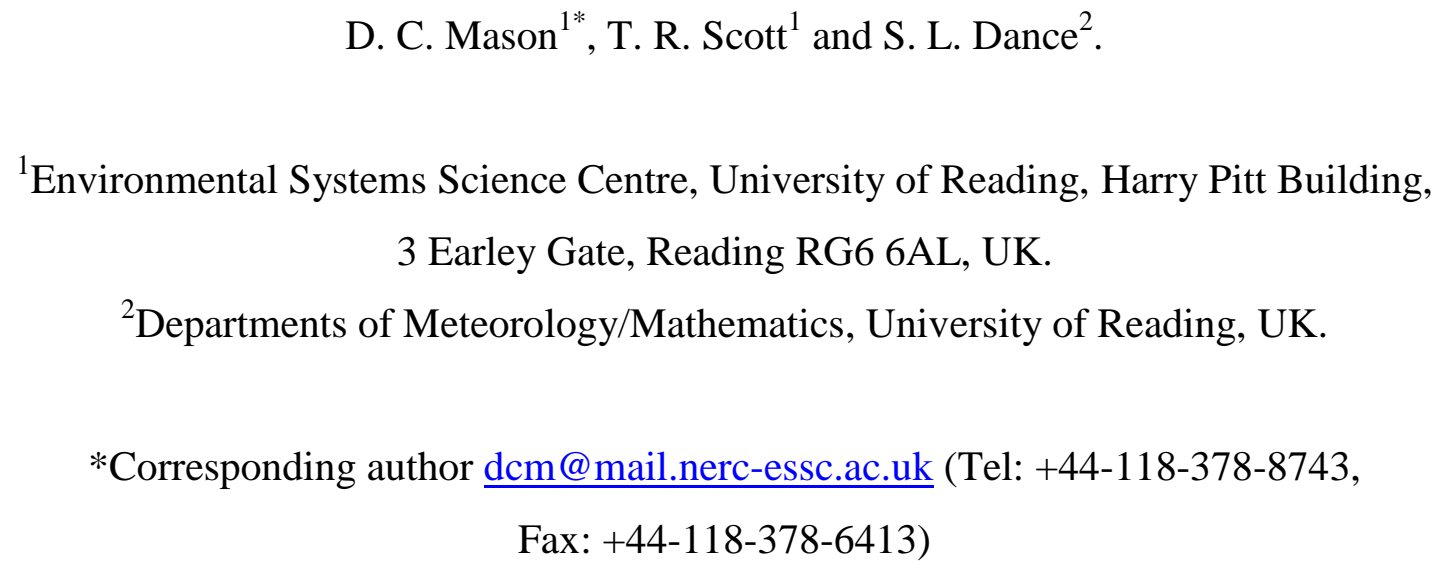
3 Earley Gate, Reading RG6 6AL, UK.

${ }^{2}$ Departments of Meteorology/Mathematics, University of Reading, UK.

*Corresponding author dcm@ mail.nerc-essc.ac.uk (Tel: +44-118-378-8743, Fax: +44-118-378-6413)

\begin{abstract}
Tidal Flats are important examples of extensive areas of natural environment that remain relatively unaffected by man. Monitoring of tidal flats is required for a variety of purposes. Remote sensing has become an established technique for the measurement of topography over tidal flats. A further requirement is to measure topographic changes in order to measure sediment budgets. To date there have been few attempts to make quantitative estimates of morphological change over tidal flat areas. This paper illustrates the use of remote sensing to measure quantitative and qualitative changes in the tidal flats of Morecambe Bay during the relatively long period 1991 - 2007. An understanding of the patterns of sediment transport within the Bay is of considerable interest for coastal management and defence purposes. Tidal asymmetry is considered to be the dominant cause of morphological change in the Bay, with the higher currents associated with the flood tide being the main agency moulding the channel system. Quantitative changes were measured by comparing a Digital Elevation Model (DEM) of the intertidal zone formed using the waterline technique applied to satellite Synthetic Aperture Radar (SAR)
\end{abstract}


31 images from 1991-4, to a second DEM constructed from airborne laser altimetry data

32 acquired in 2005. Qualitative changes were studied using additional SAR images

33 acquired since 2003. A significant movement of sediment from below Mean Sea Level

34 (MSL) to above MSL was detected by comparing the two Digital Elevation Models,

35 though the proportion of this change that could be ascribed to seasonal effects was not

36 clear. Between 1991 and 2004 there was a migration of the Ulverston channel of the river

37 Leven north-east by about $5 \mathrm{~km}$, followed by the development of a straighter channel to

38 the west, leaving the previous channel decoupled from the river. This is thought to be due

39 to independent tidal and fluvial forcing mechanisms acting on the channel. The results

40 demonstrate the effectiveness of remote sensing for measurement of long-term

41 morphological change in tidal flat areas. An alternative use of waterlines as partial

42 bathymetry for assimilation into a morphodynamic model of the coastal zone is also

43 discussed.

44

45 Keywords: remote sensing, hydrodynamic equations, temporal variations, water level

46 measurement, U.K., Morecambe Bay.

47 


\section{Introduction}

50 Tidal Flats such as those of the European Wadden Sea are present at various locations around the world, and are important examples of extensive areas of natural environment

52 that remain relatively unaffected by man. Monitoring of tidal flats is required for a variety

53 of purposes, including coastal defence, navigation, fishing, survey of wildfowl habitats

54 and salt marshes, and tourism.

56 Remote sensing has become an established technique for the measurement of topography

57 over tidal flats, due in no small part to its synoptic nature. While ground and ship surveys

58 may be able to achieve high height accuracies, these are laborious and time-consuming to

59 perform over the large areas involved. The remote sensing techniques most commonly

60 employed over tidal flats are airborne LiDAR (Light Detection And Ranging) (Flood and

61 Gutelius, 1997; Stockdon et al., 2002; Deronde et al., 2006), airborne InSAR

62 (Interferometric Synthetic Aperture Radar) (Greidanus et al., 1999; Wimmer et al., 2000)

63 and the waterline method (Collins and Madge, 1981; Koopmans and Wang, 1995; Mason

64 et al., 1995; Niedermeier et al., 2005; Kim et al., 2007; Zhao et al., 2008; Ryu et al.,

65 2008; Heygster et al, in press). Because of the cost over large areas and the logistical

66 difficulties of flying at low tide, airborne methods are normally used to survey narrower

67 beaches. The waterline method applied to satellite images remains of importance for the

68 topographic mapping of large areas of tidal flats, partly because of its relatively low cost

69 (Mason et al., 2000). The term waterline is used to denote the water's edge, which moves

70 to and fro as the tides rise and fall. The method involves finding the geo-coded positions

71 of the waterline in a remotely sensed image using image processing techniques. Predicted

72 water elevations at the waterline are superimposed on these positions. These elevations

73 may be predicted using a hydrodynamic tide-surge model run for the area for the time of

74 acquisition of the image, with the weather conditions pertaining at the time. From

75 multiple images obtained over a range of tidal conditions, a set of heighted waterlines can

76 be assembled in the intertidal zone, and from this a gridded Digital Elevation Model

77 (DEM) can be interpolated. 
79 In addition to topographic mapping, a further requirement is to measure topographic

80 changes over tidal flats occurring during a certain period in order to measure sediment

81 budgets. Ryu et al. (2008) point out that as yet there have been few attempts to make

82 quantitative estimates of morphological change over large tidal flat areas (e.g. Mason et

83 al., 1999; Ryu et al., 2008). This paper illustrates the use of remote sensing to measure

84 quantitative and qualitative changes in the tidal flats of Morecambe Bay (fig. 1) during

85 the relatively long period 1991-2007. Morecambe Bay is a macro-tidal embayment in

86 north-west England containing the largest single area of intertidal zone in Britain

$87\left(340 \mathrm{~km}^{2}\right)$. The intertidal area is very dynamic, and changes in the positions of many

88 subtidal channels and sandbanks are apparent even over a single season. An

89 understanding of the patterns of sediment transport within the Bay is of considerable

90 interest. The Cumbria Coastal Study (SMP, 1991) lists a number of areas of concern

91 around the Bay regarding coastal management and defence issues. For example,

92 shoreward movement of the Kent channel near Morecambe can make it easier for waves

93 to travel up the channel and access the coastline, increasing urban flood risk in

94 Morecambe. Whilst many problems appear to be localized, previous studies accept that

95 the cause is unlikely to be purely local and that it is necessary to adopt a more holistic

96 view of processes and sediment movement within the Bay.

98 (Fig. 1 about here)

100 Mason et al. (1999) studied intertidal sediment transport in Morecambe Bay over the

101 period 1992-7 using the waterline method. It was apparent that there was substantial

102 intertidal sediment transport over this period. This led on to attempts to model the

103 sediment transport (Mason and Garg, 2001; Scott and Mason, 2007), in the latter paper by

104 assimilating partial bathymetry from waterlines into the morphodynamic model run to

105 keep the model 'on track' and improve its ability to predict future sediment transport. The

106 advantages of performing data assimilation within a morphodynamic model run are

107 currently being studied further, and this has led to the acquisition of a good deal of

108 modern-day intertidal bathymetry. Whilst the separation in time is too large and the

109 intermediate data too sparse for the two periods to be linked by morphodynamic 
110 modelling using assimilation, it was felt that useful information could be obtained by

111 comparing the modern intertidal bathymetry with that from the early 1990s. The

112 evolution of the low-water channels could be studied over a 16-year period, perhaps

113 allowing the detection of discernable patterns. The intertidal sediment budget over the

114 period could also be estimated quantitatively. These are the objectives of this short

115 communication. In practical terms, at present this is probably almost the longest time

116 period over which intertidal morphological change can be measured quantitatively at this

117 site using remote sensing. The low rate of acquisition of suitable images from visible

118 band sensors due to frequent cloud cover over the Bay, coupled with the rapidity with

119 which morphological change can occur, mean that it is unlikely that an accurate DEM of

120 the intertidal zone could be produced using the waterline method prior to the launch of

121 the ERS-1 SAR sensor in 1991.

\section{$123 \quad 2$. Study area}

125 Morecambe Bay is an estuary which serves as an interface between the open sea and its

126 four primary feeder rivers, the Kent and Leven in the north and the smaller Lune and

127 Wyre in the south. Intertidal sand and mud banks form the dominant coastal landforms in

128 the Bay, representing $68 \%$ of its total area, with the remainder being composed of large

129 subtidal channels and saltmarsh. A detailed description of the Bay, including its tide and

130 wave climates and sediment composition, has been given in (Mason et al., 1999), and

131 only a summary is presented here.

133 The Bay has a large ordinary spring tidal range of about $8.2 \mathrm{~m}$ at Morecambe. The

134 duration of the semi-diurnal ebb and flood tides are unequal, with the ebb running for

135 about 40 minutes longer that the flood at Heysham (Coomber and Hansom, 1994). In the

136 large subtidal channels, the spring tide attains a maximum velocity of about $1.5 \mathrm{~ms}^{-1}$, with

137 currents being higher on the flood than the ebb. The wave climate of the area is

138 dominated by smaller waves, as wave sizes are limited by the restricted fetch due to the

139 sheltering landmasses of Ireland, the Isle of Man and spits at the mouth of the Bay. The

140 sediments in the intertidal zone are predominantly composed of very fine and fine sand 
$141(0.06-0.2 \mathrm{~mm})$, with coarser sand and fine gravel at the mouth of the Bay and silts in the 142 inner Bay (SMP, 1996). Tidal asymmetry is considered to be the dominant cause of 143 morphological change in the Bay, with the higher currents associated with the flood tide 144 being the main agency moulding the channel system (Pringle, 1987). Sediment transport 145 in the Bay has been investigated in a number of studies (e.g. McClaren, 1989; Kestner, 146 1970). Coomber and Hanson (1994) point out the importance of quantifying the sediment 147 budget in order to formulate effective management policies for the Bay. On the basis of

148 limited evidence from past patterns of erosion and deposition, it appears that the sediment 149 budget for the inner Bay is essentially positive, while that for the outer Bay is negative, 150 with net import of sediment into the Bay being small.

\section{3. Data sets}

154 The study compared an older data set of SAR images acquired between 1991 and 1994 155 with a modern data set comprised of further SAR images acquired since 2003 together 156 with scanning airborne laser altimetry (LiDAR) data. In order to estimate the intertidal 157 sediment budget over the period, two Digital Elevation Models (DEMs) were constructed 158 from these data.

160 A DEM for 1992-4 (fig. 2a) was constructed using the waterline method. The DEM was 161 constructed from 18 ERS SAR images acquired between late 1991 and 1994. SAR 162 images were used because of their all-weather, day-night capability, allowing a set of 163 images at various stages of the tidal cycle to be acquired in a reasonably short time.

164 Details of the method of construction are given in (Mason et al., 1999), and only a 165 summary is presented here. DEM construction involved waterline delineation and 166 registration, determination of waterline elevations and interpolation of a set of waterlines. 167 Waterlines were delineated using a semi-automatic technique in which sea regions were 168 first detected as regions of low edge density in a low resolution version of a SAR image, 169 then image edges along the waterline were extracted using more elaborate processing at 170 high resolution based on an active contour model. Waterline elevations were determined 171 using the Proudman Oceanographic Laboratory’s Morecambe Bay tide-surge model 
172 having a 240m grid size. Modelled water elevations were corrected using readings from

173 the tide gauge at Heysham measured relative to Ordnance Datum Newlyn (ODN).

174 Interpolation in space and time was carried out using block kriging to produce a

175 continuous spatiotemporal DEM of the intertidal zone having a spatial resolution of $50 \mathrm{~m}$

176 and height accuracy of about $40 \mathrm{~cm}$. Strong temporal decorrelation of heights in the Bay

177 limited the height accuracy achievable. The DEM was constructed from SAR images

178 acquired prior to the introduction of height measurement using scanning airborne

179 LiDARs.

181 The LiDAR DEM (fig. 2b) was constructed from data provided by Lancaster City

182 Council that were obtained by over-flying the Bay at low tide during November 2005.

183 The area covered included almost the complete intertidal zone. The data had a spatial

184 resolution of $2 \mathrm{~m}$, and the complete data set included almost 200 million samples. To

185 match the resolution of the waterline DEM, the data were averaged to blocks of side $50 \mathrm{~m}$.

186 Because of the high cost of acquiring and processing the data for the large area involved,

187 and the logistical difficulty of overflying the Bay at low tide, such a large LiDAR dataset

188 of a region of tidal flats remains a rarity.

190 (Fig. 2 about here)

\section{Results}

\subsection{Intertidal sediment budget}

An attempt was made to estimate the absolute intertidal sediment budget of the Bay over

197 a 12-year period by comparing the two DEMs of the intertidal zone. Fig. 2c shows the

198 height changes that have occurred over the 12-year period at each grid cell of the intertidal zone for which a height exists in both DEMs. Areas of erosion are indicated by

200 blue/purple colours and areas of accretion by orange/red. From fig. 2c, the mean height

201 change in the intertidal zone over this time was estimated to be $1.1 \mathrm{~cm}$. A considerable

202 error is associated with this figure. In (Mason et al., 1999), the waterline heights at 
203 Heysham predicted by the tide-surge model were regressed against the heights of the

204 Heysham tide gauge at the times of the image acquisitions, and found to have a mean

205 height difference of $-11.6 \mathrm{~cm} \pm 6.7 \mathrm{~cm}$ and a standard deviation of $15.8 \mathrm{~cm}$. The random

206 component of the error is subsumed into the block kriging height error (see below), but,

207 while the mean height difference is corrected for in the waterline height calculation, its

208 error is an additional component that must be taken into account in the sediment budget

209 calculation. For the LiDAR data, the LiDAR height standard deviation was estimated to

210 be $6 \mathrm{~cm}$ by sampling heights from flat surfaces. The error in the mean LiDAR height was

211 estimated by comparing LiDAR heights with independently-surveyed heights at a number

212 of positions in flat urban areas around the Bay, and was found to be $1 \pm 5 \mathrm{~cm}$. Given the

213 magnitudes of the errors on the mean heights together with the block kriging errors on the

214 waterline DEM, no significant change could be detected in the absolute intertidal

215 sediment budget.

217 However, it was possible to estimate the relative change in intertidal sediment volume

218 from below MSL to above MSL by normalising the 2005 LiDAR heights to have the

219 same mean height as the 1992-4 DEM, thus eliminating the errors on the biases of the

220 two data sets. Table 1 gives the relative change in sediment volume above MSL after

221 normalisation, obtained by subtracting the 1992-4 DEM heights from the normalised

2222005 LiDAR heights in the area above MSL in the 1992-4 DEM. The relative change in

223 sediment volume below MSL in table 1 was calculated in similar fashion.

225 The table also gives the random errors on these volumes calculated by the method given

226 in the Appendix of (Mason et al., 1999). These errors are based on the block kriging

227 errors on the individual 50m blocks resulting from the waterline interpolation procedure.

228 Although block kriging errors are calculated using only the geometric relationship

229 between an interpolated block and its sample points (Journel, 1989), their sizes correlated

230 reasonably well with errors between the kriged estimates and the validation data used in

231 (Mason et al., 1999). In the latter paper, the variances of a set of 50m blocks were

232 combined by taking into account the spatial correlations between the blocks estimated

233 using their variogram. Thus the error on the relative change in sediment volume above 
234 MSL in table 1, for example, is the square root of the combined variance of all the 50m

235 blocks in the area above MSL.

237 The relative volume change above MSL in table 1 was compared to its error to test

238 whether the change was significantly non-zero. Assuming a normally distributed variable,

239 the change was consistent with being zero at the $95 \%$ confidence level, so that no

240 significant change was found. The same was true for the relative volume change below

241 MSL. However, if the total relative volume change from below to above MSL was

242 calculated by subtracting the relative volume change below MSL from that above MSL,

243 there was a significant positive change at the 95\% confidence level (table 1). Thus a

244 significant movement of sediment from below MSL to above MSL appears to have

245 occurred over the 12-year period. It is not clear how much of this movement may be

246 ascribed to the fact that a seasonal effect may have been present in the LiDAR DEM

247 acquired in November 2005, whereas this could have been averaged out in the waterline

248 DEM. The slope of the intertidal zone may be higher in summer than in winter due to

249 gentler wave action in summer (Komar, 1998), and the LiDAR DEM was acquired before

250 the winter storm season had begun.

\subsection{Tidal channel migration}

254 A number of significant morphological changes in the Bay are apparent in the SAR

255 images over the period. Fig. 2c shows that the most significant change in terms of

256 sediment volume is that of the Ulverston channel in the Leven estuary. Fig. 3 shows a

257 sequence of SAR images of the Bay acquired at low-water between August 1991 and

258 February 2007, which depicts the evolution of this channel over a 16-year period.

259 Between 1991 and 2004 there is a gradual but substantial migration of the channel north-

260 east by about $5 \mathrm{~km}$, cutting into Cartmel Wharf. This movement appears to have been

261 ongoing since at least 1970, since fig. 1 (based on O.S. maps revised in 1968-71) shows

262 the channel lying even further to the west than in August 1991. An intermediate

263 observation shows that the channel migrated $2 \mathrm{~km}$ to the north-east between 1991 (fig. 3a)

264 and 1996 (fig. 3b) (Mason et al., 1999). A change in this pattern occurred between May 

2004 (fig. 3d) and November 2005 (fig. 3e). By November 2005, a straighter Ulverston

266 channel had developed to the west, leaving the previous curved channel decoupled from 267 the river Leven. Higher land on Cartmel Wharf now formed a barrier between the end of 268 this cul-de-sac and the new channel of the Leven (the proximity of the higher land to the 269 channel can be clearly seen at A in fig. 2b). Two transects sampled across the curved 270 section of the cul-de-sac channel from the LiDAR data of November 2005 are shown in 271 fig. 2b. For both transects, the slope of the outer bank of the curve is higher than that of 272 the inner bank, which is consistent with the outer bank being eroded, even though the 273 slopes involved are very low $\left(0.1^{\circ}-2 \cdot 7^{\circ}\right)$. It is not known if this pattern of migration is 274 cyclical, but if it is, the period of the cycle must be greater than 16 years, since Cartmel 275 Wharf in 2007 (fig. 3f) exhibited three main intrusions, the new Ulverston channel, the 276 cul-de-sac channel and the Kent channel, whereas in 1991 (fig. 3a) only the Kent and old

277 Ulverston channels were present. This example of tidal channel migration is discussed 278 further in the following section.

280 (Fig.3 about here)

282 The other main morphological changes that have occurred relate to the Kent and Lune 283 estuaries. In the Kent estuary, accretion has occurred on the west bank near Grange-over284 Sands during the period, together with erosion of the Silverdale Marsh on the east 285 (though some accretion south-west of Jenny Brown's Point is apparent) (fig. 2c). This can 286 be explained by a net migration of the Kent low-water channels to the east over the 287 period, continuing a trend that was apparent between 1991 and 1996 (Mason et al., 1999). 288 Movements of the Kent channel over the last century and their consequent effects have 289 been discussed in (Mason et al., 1999). In the Lune estuary, the appearance of a 290 significant north-westerly channel and the decline of the westerly channel occurred 291 between 1991 (fig. 3a) and 1996 (fig. 3b), and has been discussed in (Mason et al., 1999).

292 This change appears to have been largely maintained until 2007 (fig. 3f).

294 A point of technical interest regarding the SAR images of fig. 3 is the wide variation in 295 backscatter that they display in the intertidal zone. The sequence consists of three ERS 
296 and three ASAR images having the same VV polarization, with three descending and

297 three ascending pass images, and with the ASAR images having slightly different look

298 angles to the ERS images. However, this phenomenon can also be seen in different

299 images of the ERS sensor on the same pass direction (Mason et al., 1999). All the images

300 were obtained near low water, so that the differences are unlikely to be due to

301 acquisitions being at different stages of the tidal cycle. Low backscatter from tidal flats is

302 symptomatic of smooth wet surfaces acting largely as specular reflectors. High

303 backscatter can occur if there are ripples on the surface aligned parallel with the satellite

304 track (as these provide scattering surfaces more perpendicular to the incident radiation),

305 or if the sand is dry due to wind and lack of rain.

\section{Discussion}

The movement of the Ulverston channel over the 16-year period is an interesting example of tidal channel migration. Tidal channel migration in tidal flat areas has been

311 investigated in several studies (Ginsberg et al., 2004; Oost and de Boer, 1994; Asp,

312 2006). Ginsberg et al. (2004) found that tidal channels in the Bahia Blanca Estuary

313 migrated laterally at a rate of about $25 \mathrm{~m}$ per year, though the sediment involved was

314 more cohesive than in Morecambe Bay. Oost and de Boer (1994) measured migration

315 rates of $100 \mathrm{~m}$ per year in areas of the Dutch Wadden Sea. In this case, the Ulverston

316 channel migrated about $5 \mathrm{~km}$ in 13 years, a rate of about $400 \mathrm{~m}$ per year. A possible cause

317 of the channel becoming sinuous in the first instance may be that the general direction of

318 the high currents on the flood tide is south-west to north-east (Mason et al., 1999),

319 whereas the Ulverston channel is oriented south-east to north-west, thus creating a

320 component of helical flow in the water entering the channel. Once sinuosity had been

321 established, the helical flow would result in further erosion on the outer bank and

322 deposition on the inner bank, resulting in increased channel curvature and increased

323 helical flow (Hickin, 2003). After May 2004, the channel cut into higher land on Cartmel

324 Wharf forming a barrier between it and the river Leven. The high currents of the flood

325 tide would have gradually reduced as they cut into the higher land. In addition, Lanzoni

326 and Seminara (2002) have shown that tidal asymmetry characterised by higher currents 
on the flood tide (as is present in Morecambe Bay) induces a land-directed sediment

328 transport, which may have led to increased sedimentation on Cartmel Wharf. Unable to

329 breach the higher land, the river Leven reverted to its older straighter channel. The

330 underlying cause of this pattern of migration is probably that there are two independent

331 forcing mechanisms, the greater tidal forces and the lesser fluvial flow, which act

332 independently of each other. Rinaldo et al. (1999), in their study of tidal channel

333 networks, found that parts of a network may be flood-dominated and others ebb-

334 dominated.

336 As noted previously, the waterline method applied to satellite images remains of

337 importance for the topographic mapping of tidal flats. A difficulty with the method is that

338 it assumes that changes in the intertidal zone are small over the time taken to acquire the

339 image sequence used to construct the intertidal DEM. Given the rapidity with which

340 changes can occur in the Bay, and the fact that in 1991 only the SAR sensor on board

341 ERS-1 was available, there was considerable temporal decorrelation between waterlines

342 over the 3-year period during which SAR images were selected, and this limited the

343 vertical accuracy of the Morecambe Bay DEM for 1992-4 to 40cm. This can be compared

344 with the $10 \mathrm{~cm}$ accuracy achieved by Ryu et al. (2008) in their study of more stable

345 Korean tidal flats. These authors also achieved a higher accuracy of waterline heighting

346 than that reported by Mason et al. (1999) by using direct levelling of waterlines and

347 assuming each waterline was a contour of uniform height, rather than using a

348 hydrodynamic model to height waterlines. In Morecambe Bay, waterlines were heighted

349 using a hydrodynamic model and tide gauge data because significant height differences

350 could occur along a waterline between the inner and outer parts of the Bay.

352 An alternative method of using the information from waterlines that does not suffer from

353 this disadvantage and does not involve constructing a DEM is to use the waterlines as a

354 source of partial bathymetry that can be assimilated into a coastal area morphodynamic

355 model. Such models can provide information on how the morphology of the coast is

356 evolving in response to natural or man-made causes. Morphodynamic models often

357 perform poorly in detail, partly because the physical processes (tides, waves, etc) that 
358 drive morphological change occur on much shorter timescales than the changes

359 themselves (de Vriend, 1993). One approach to improving model performance is to use

360 data assimilation to combine the modelled bathymetry with observations of bathymetry,

361 and waterlines are one type of observation that can be used. Scott and Mason (2007)

362 developed a morphodynamic model of Morecambe Bay that was enhanced by using

363 optimal interpolation to assimilate waterline heights to better predict large-scale

364 bathymetric changes in the Bay over a 3-year period (fig. 4). Waterlines were assimilated

365 into the model run sequentially at the times at which they were acquired. Whilst each

366 SAR image only contains bathymetric information along its waterline, the latter's heights

367 influenced the modelled heights not only of the model grid cells that it overlayed, but also

368 those of neighbouring cells, thus spreading its information over a larger area. Fig. 4a

369 shows the observed changes in intertidal bathymetry over the period 1994-7. Fig. 4b

370 shows the modelled changes in bathymetry over the same period without using data

371 assimilation, showing that the main areas of accretion were predicted but not the area of

372 erosion along the Ulverston channel. Fig. $4 \mathrm{c}$ shows the modelled changes in bathymetry

373 using assimilation of waterlines, when the erosion along the Ulverston channel was

374 correctly predicted. A further advantage of using waterlines in this way is that any

375 seasonal effects present in the waterline heights are automatically taken into account. If a

376 DEM is constructed from waterlines, ideally images should be acquired during a single

377 season to reduce seasonal variations, but this may be difficult to achieve in practice (Ryu

378 et al., 2008).

\section{6. Conclusions}

382 The study has demonstrated the effectiveness of remote sensing for qualitative and

383 quantitative measurement of long-term morphological change in tidal flats areas, using as

384 example the intertidal zone of Morecambe Bay. A significant movement of sediment

385 from below MSL to above was detected by comparing DEMs for 1992-4 and 2005,

386 though the proportion of this increase that could be ascribed to seasonal effects was not

387 clear. Between 1991 and 2004 there was a migration of the Ulverston channel north-east

388 by about $5 \mathrm{~km}$, followed in 2004 by the development of a straighter Ulverston channel to 
the west, leaving the previous curved channel decoupled from the river Leven. This is

390 thought to be due to two independent forcing mechanisms acting on the channel. An

391 alternative use of waterlines is as partial bathymetry for assimilation into a

392 morphodynamic model, instead of simply being used for construction of an intertidal

393 DEM.

\section{Acknowledgements}

This work was partly funded under the NERC Flood Risk from Extreme Events (FREE)

398 Research Programme (grant NE/E002048/1). Thanks are due to Nigel Cross of Lancaster

399 City Council for the provision of the LiDAR data. This paper is dedicated to the memory 400 of Nigel Cross.

Asp, N.E., 2006. Morphological changes of tidal flats at the German North Sea Coast induced by tidal asymmetry. Journal of Coastal Research Sp. Iss. 39, 440-445.

Collins, B.J. and Madge, B., 1981. A new method for monitoring beach movement. Chartered Land Surveyor/Chartered Minerals Surveyor 3, 4-11.

Coomber, D.P.M., Hansom, J.D., 1994. Estuaries Management Plans: Coastal Processes and Conservation, Morecambe Bay. Coastal Research Group, University of Glasgow, 79pp.

Deronde, B., Houthuys, R., Debruyn, W., Fransaer, D., Lancker, V.V., Henriet, J.P., 2006. Use of airborne hyperspectral data and laser scan data to study beach morphodynamics along the Belgian Coast. Journal of Coastal Research 22, 1108-1117.

de Vriend, H.J., Capobianco, M., Chesher T., de Swart, H.E., Latteux, B., Stive, M.J.F.,1993. Approaches to long-term modelling of coastal morphology: a review. Coastal Engineering 21, 225-269.

Flood, M., Gutelius, B., 1997. Commercial implications of topographic terrain mapping using scanning airborne laser radar. Photogrammetric Engineering and Remote Sensing 63, 327-366.

Ginsberg, S.S., Perillo, G.M.E., 2004. Characteristics of tidal channels in a mesotidal estuary of Argentina. Journal of Coastal Research 20(2), 489-497. 
Greidanus, H., Huising, E.J., Platschorre, Y., van Bree, R.J.P., van Halsema, D., Vaessen,

E.M.J.,1999. Coastal DMs with cross-track interferometry. IEEE Proceedings of

International Geoscience and Remote Sensing Symposium, Hawaii, USA, pp. 1889-1891.

Heygster, G., Dannenberg, J., Notholt, J. (in press). Topographic mapping of the German tidal flats analysing SAR images with the waterline method. IEEE. Trans. Geoscience and Remote Sensing.

Hickin, E.J., 2003. Meandering channels. In: G. V. Middleton, (Editor), Encyclopedia of Sediments and Sedimentary Rocks. Kluwer Academic Publishers, London, pp. 434-435.

Journel, A.G., 1989. Fundamentals of geostatistics in five lessons. American Geophysical Union.

Kestner, F.J.T., 1970. Cyclic changes in Morecambe Bay. Geographical Journal 136, 8597.

Kim, D., Moon, W.M., Park, S-E., Kim, J., Lee,, H-S. 2007. Dependence of waterline mapping on radar frequency used for SAR images in intertidal areas. IEEE Geoscience and Remote Sensing Letters 4(2), 269-273.

Komar, P.D., 1998. Beach processes and sedimentation, $2^{\text {nd }}$ edn, Englewood Cliffs NJ : Prentice-Hall.

Koopmans, B.N., Wang Y., 1995. Measurement of land-sea transition from ERS-1 SAR images at different phases of tidal water. Netherlands Remote Sensing Board Report 9520,64 .

Lanzoni, S., Seminara, G., 2002. Long-term evolution and morphodynamic equilibrium of tidal channels. Journal of Geophysical Research 107, NO. C1, 10.1029/2000JC000468, $1-13$.

Mason, D.C., Davenport, I.J., Flather, R.A., McCartney, B., Robinson, G.R., 1995, Construction of an intertidal digital elevation model by the 'waterline' method.

Geophysical Research Letters 22, 3187-3190.

Mason, D.C., Amin, M., Davenport, I.J., Flather, R.A., Robinson, G.J., Smith, J.A., 1999. Measurement of recent intertidal sediment transport in Morecambe Bay using the waterline method. Estuarine, Coastal and Shelf Science 49, 427-456.

Mason, D.C., Gurney, C., Kennett, M., 2000. Beach topography mapping - a comparison of techniques. Journal of Coastal Conservation 6, 113-124.

Mason, D.C., Garg, P.K., 2001. Morphodynamic modelling of intertidal sediment transport in Morecambe Bay. Estuarine, Coastal and Shelf Science 53, 79-92. 
McClaren, P., 1989. The sediment transport regime in Morecambe Bay and the Ribble estuary. Report commissioned by North West Water from GeoSea Consulting (U.K.) Ltd., June 1989, 41pp. German Bight using SAR and optical remote sensing data. Ocean Dynamics, 55(2), 100109.

481 Oost, A., de Boer, P.L., 1994. Sedimentology and development of barrier islands, ebbtide deltas, inlets and backbarrier areas of the Dutch Wadden Sea. Senckenbergiana maritima 24, 63-115.

Pringle, A.W., 1987. Physical processes shaping the intertidal and subtidal zones. In: N.A. Robinson and A.W. Pringle, (Editors), Morecambe Bay: an assessment of present ecological knowledge, University of Lancaster, pp. 51-73.

Rinaldo, A., Fagherazzi, S., Lanzoni, S., Marani, M., Dietrich, W.E., 1999. Tidal networks 3. Landscape-forming discharges and studies in empirical geomorphic relationships. Water Resources Research 35, 3919-3929.

Ryu, J-H., Kim, C-H., Lee, Y-K., Won, J-S., Chun, S-S., Lee, S., 2008. Detecting the intertidal morphologic change using satellite data. Estuarine, Coastal and Shelf Science $78,623-632$.

Scott, T.R., Mason, D.C., 2007. Data assimilation for a coastal area morphodynamic model: Morecambe Bay. Coastal Engineering 54, 91-109.

Shoreline Management Partnership (SMP), 1991. Cumbria Coastal Study (Baseline Report). Report to the Cumbria Coastal Consortium.

Shoreline Management Partnership (SMP), 1996. Morecambe Bay Shoreline Management Plan (Consultation Document) Stage 1 Volume 2. Report to the Cumbria Coastal Consortium.

Stockdon, H.F., Sallenger Jr., A.H., Jeffery, H.L., Holman, R.A., 2002. Estimation of shoreline position and change using airborne topographic lidar data. Journal of Coastal Research 18, 502-513.

Wimmer, C., Siegmund, R., Schwabisch, M., Moreira, J., 2000. Generation of high precision DEMs of the Wadden Sea with airborne interferometric SAR. IEEE Transactions on GeoScience and Remote Sensing 38, 2234-2245.

Zhao, B., Guo, H., Yan, Y., Wang, Q., Li, B., 2008. A simple waterline approach for tidelands using multi-temporal satellite images: a case study in the Yangtze Delta. Estuarine, Coastal and Shelf Science 77, 134-142. 
518 Table 1. Relative sediment volume changes in the intertidal zone between 1992-4 and 519 November 2005.

520

\begin{tabular}{|c|c|c|c|c|}
\hline $\begin{array}{c}\text { Intertidal } \\
\text { region }\end{array}$ & $\begin{array}{c}\text { Area } \\
\left(\mathbf{k m}^{\mathbf{2}}\right)\end{array}$ & $\begin{array}{c}\text { Mean height } \\
\text { change }(\mathbf{c m})\end{array}$ & $\begin{array}{c}\text { Volume change } \\
\left(\mathbf{m}^{\mathbf{3}} \mathbf{x} \mathbf{1 0}^{\mathbf{6}}\right)\end{array}$ & $\begin{array}{c}\text { Error } \\
\left(\mathbf{m}^{\mathbf{3}} \mathbf{x} \mathbf{1 0}^{\mathbf{6}}\right)\end{array}$ \\
\hline Above MSL & 192 & 1.8 & 3.5 & 2.1 \\
\hline Below MSL & 117 & -3.1 & -3.7 & 1.9 \\
\hline Total & & & 7.1 & 2.9 \\
\hline
\end{tabular}


1. Morecambe Bay (based on O.S. 1:25,000 maps (revised 1968-71) (after Mason et al., 1999).

2. Morecambe Bay DEMs for (a) 1992-4, (b) November 2005, and (c) height changes between 1992-4 and November 2005.

531 3. ERS and ASAR sub-images showing the low water channels in Morecambe Bay from (a) August 1991 (-2.1m ODN), (b) November 1996 (-2.3m ODN), (c) June 2003 (-2.3m ODN), (d) May 2004 (-2.6m ODN), (e) November 2005 (-1.3m ODN), and (f) February 2007 (-2.5m ODN).

4. Change in Morecambe Bay intertidal bathymetry over the period 1994-7, (a) observed change, (b) modelled change without data assimilation, (c) modelled change with assimilation of waterlines (after Scott and Mason, 2007). 